\title{
Femoral Intertrochanteric Fractures of the Patients in the Emergency Department due to Minor Falls: Special Consideration in the Middle-old to Oldest-old Patients
}

\author{
Jung Min Jang ${ }^{1}$, Han Sung Choi ${ }^{1,2}$, Jong Seok Lee ${ }^{1,2}$, Ki Young Jeong ${ }^{1,2}$, Hoon Pyo Hong ${ }^{1,2}$, Seok Hoon Ko ${ }^{1,2}$ \\ ${ }^{1}$ Department of Emergency Medicine, Kyung Hee University Hospital, Seoul, Korea \\ ${ }^{2}$ Department of Emergency Medicine, College of Medicine, Kyung Hee University, Seoul, Korea
}

Corresponding Author:

Han Sung Choi, MD, PhD

Department of Emergency Medicine,

Kyung Hee University Hospital, 23

Kyungheedae-ro, Dongdaemun-gu,

Seoul 02447, Korea

E-mail: hsg3748@hanmail.net

ORCID:

https://orcid.org/0000-0001-7477-5405

Received: July 17, 2019

Revised: September 10, 2019

Accepted: September 17, 2019
Background: The older population ( $\geq 65$ years) has rapidly increased in size in recent years. Among them, the middle-to-oldest-old ( $\geq 75$ years) tend to have a poor health status. Therefore, subdivision and evaluation of older patients with traumatic injury are required. We focused on the risk of femoral intertrochanteric fractures occurring in older adults due to minor falls and compared young-old and middle-to-oldest-old populations. Methods: The medical records of patients who visited the emergency center due to hip injuries between March 2017 and March 2019 were retrospectively analyzed. Patients were divided into older adult ( $\geq 65$ years) and non-older (age 18-64 years) groups; the older adult group was subdivided into young-old (65-74 years), middle-old ( $75-84$ years), and oldest-old ( $\geq 85$ years) groups. This study investigated the occurrence rate of femoral intertrochanteric fractures and related factors. Results: The older adult group had a higher incidence of femoral intertrochanteric fractures than that in the non-older adult group ( $95.3 \%$ vs. $4.7 \%, p<0.001)$. However, there was no significant difference between young-old and non-older groups ( $58.8 \%$ vs. $41.2 \%, p=0.145$ ). Middle-old to oldest-old age and osteoporosis were associated with an increased incidence of femoral intertrochanteric fractures $(p<0.001, p=0.004)$. Conclusion: A higher incidence of femoral intertrochanteric fractures from minor falls was found among middle-old to oldest-old patients compared to that in young-old patients. Therefore, physicians should perform more thorough physical examinations and radiograph reading in middle-old to oldest-old patients even if the patients do not complain of pain.

Key Words: Older adults, Accidental falls, Intertrochanteric fractures, Emergency

\section{INTRODUCTION}

The proportion of the older population aged $\geq 65$ years in Korea was about $14.1 \%$ in 2015 and is expected to increase to greater than $20 \%$ by 2025 , becoming a so-called 'super-aged society.' ${ }^{, 1)}$ This is the fastest annual aging rate in the world. ${ }^{2)}$ With a rapid increase in the older population, the lack of medical research focusing on the older population is a major concern. ${ }^{1)}$ The increase in the older adult population leads to their increased participation in social and leisure activities, thus increasing the frequency of trauma in this popula- tion. Furthermore, aging is significantly associated with decreased physiological ability, which is a cause of trauma, requiring special medical needs and treatment compared to other age groups.

Injuries from falls are the most common and major cause of trauma in older adults. ${ }^{4,5)}$ This age group has a higher frequency and risk of falls than those of younger age groups. Falls among older adults also cause severe spontaneous damages and complications. ${ }^{6,7)}$ Generally, as the number of older individuals hospitalized has increased recently, minor falls have also increased. ${ }^{8)}$ The injuries and damage sustained from minor falls are more severe in older adults than 
those in non-older age groups. ${ }^{9-11)}$

Many people visit emergency centers due to hip injuries caused by minor falls. Hip fractures are more likely to occur in older than in younger patients. ${ }^{12)}$ Femur intertrochanteric fractures, usually caused by minor falls in older adults with osteoporosis, are the most common type of fracture around the hip. ${ }^{13)}$ The frequency of femur intertrochanteric fractures is climbing due to the increased average life expectancy of older adults. ${ }^{13)}$ Furthermore, diagnosis of these fractures may not be possible by simple plain radiography, ${ }^{14,15)}$ thus, careful interpretation of radiographs and physical examination may be needed. ${ }^{14)}$

In younger patients, fractures are rare and more likely to be diagnosed because of severe resting pain. However, older patients usually experience more fractures than expected and less often complain of pain than younger individuals. ${ }^{16)}$ Hence, increased time and effort are needed for the diagnosis of older patients with hip injuries caused by minor falls. ${ }^{17)}$

As the overall health status of older adults has gradually increased, their health conditions vary depending on their age. Therefore, the older adult population may have to be subdivided. Although the criteria differ, several studies have proposed divisions of this group into early and late ( 75 years) old age or young-old, middle-old, and oldest-old age for 65-74, 75-84, and at least 85 years, respectively. ${ }^{18-20)}$ In Korea, the proportion of older individuals aged $>85$ years is increasing rapidly, from approximately 60,000 in 1980 to an estimated 530,000 by 2015 and 1.15 million by 2026, the highest increase rate among all age groups. ${ }^{1,2}$

Among older adults, the young-old have remained healthier than their counterparts in the past due to their better economic and nutritional status and frequent medical checkups. Therefore, the degree of damage and aftereffects that they acquire may differ for various traumas. Additionally, we have observed a rapid increase in the frequency of older patients visiting the emergency centers and who are diagnosed with intertrochanteric fractures due to minor fall injury. However, to our knowledge, no studies have yet been conducted to determine the incidence of femur intertrochanteric fractures among the rapidly increasing hip injuries of older adults. ${ }^{21)}$

Therefore, we investigated the differences in the incidence of femoral intertrochanteric fracture with age. Additionally, we aimed to determine the ages of patients who should be actively diagnosed with intertrochanteric fractures through examinations such as computed tomography (CT) scans.

\section{MATERIALS AND METHODS}

\section{Patients}

The present study retrospectively reviewed the medical records of patients $>18$ years of age who visited the emergency center due to hip injuries between March 2017 and March 2019. This emergency center is a local emergency center located in Seoul that sees approximately 30,000 patients annually. During the study period, 893 patients with hip injuries visited our emergency center, approximately 851 of whom were $>18$ years of age.

Among these, 598 patients were included in the study. The reasons for exclusion included a mechanism of injury that was not a fall or was unclear, the patient was transferred to another hospital, missing or incorrect medical records, or lack of examination due to patient refusal or death upon visit. The study was approved by the Institutional Review Board of Kyung Hee University Hospital (No. KHUH 2019-07-050). Written informed consents were obtained.

\section{Study Protocols}

The target patients were divided into those aged $>65$ years (older patients) and those aged 18-64 years (non-older patients). The older patients were then classified as young-old (aged 65-74 years), middle-old ( $75-84$ years), or oldest-old ( $>85$ years). Falls were defined as 'unexpected falls to the floor or other low position, without loss of consciousness. ${ }^{, 22}$ Minor falls were defined as 'falling from a sitting or standing position to the ground, from a height of less than 1 meter, and below three steps' and other cases were excluded. ${ }^{23)}$ The medical records of patients were reviewed to determine the age, sex, time of accident, drinking alcohol at the time of accident, hip radiograph findings, underlying diseases, and prognosis. The time of accident was defined as the time of the accident described by the patient or caregiver. Drinking alcohol was determined based on the patient's smell and caretaker and paramedic statements. All hip radiograph examinations were read by imaging specialists and were assessed for the possible presence of femur intertrochanteric fractures. The type of intertrochanteric fracture was classified using Tronzo classification. ${ }^{24)}$ Underlying diseases included stroke, osteoporosis, Parkinson disease, dementia, and cancer, which are known to affect low-energy fall injury and eventually cause femur intertrochanteric fracture. ${ }^{25)}$ The prognosis was for patients hospitalized with femoral intertrochanteric fractures and, as of the time of discharge, discharged without complications was classified as a favorable prognosis, while cases of transfer or death due to complications were classified as unfavorable prognosis.

\section{Statistical Analysis}

The analysis of collected data was performed using PASW Statistics version 18.0 for Windows (SPSS Inc., Chicago, IL, USA). Data on categorical and continuous variables were presented as percentages and mean \pm standard deviation, respectively. In univariate analysis, categorical variables were analyzed using chi-squared or Fisher exact 
tests; normally-distributed continuous variables were analyzed using independent t-tests (Student t-tests) and normal distributions were analyzed using Shapiro-Wilk tests. Binary logistic regression analysis was performed on variables with significant results in univariate analysis. Findings were considered statistically significant if $\mathrm{p}<0.05$.

\section{RESULTS}

A total of 893 patients visited the emergency medical center during the study, including patients with pelvic damage. Among these, 598 patients were included in the study, except for 42 patients who were $<18$ years of age, 134 patients who were not aware of the causes of their minor falls, 83 patients who were from other hospitals, 34 patients who had missing or incorrect information in their medical records, and 2 patients who did not undergo any examination. Among the patients included in the study, 162 were aged $18-$ 64 years, 117 were in the young-old group (65-74 years), 217 were in the middle-old group (75-84 years), and 102 were in the oldest-old group ( $>85$ years) (Fig. 1).

A total of 150 patients had femur intertrochanteric fractures; the

Total patients with hip fractures $(\mathrm{n}=893)$

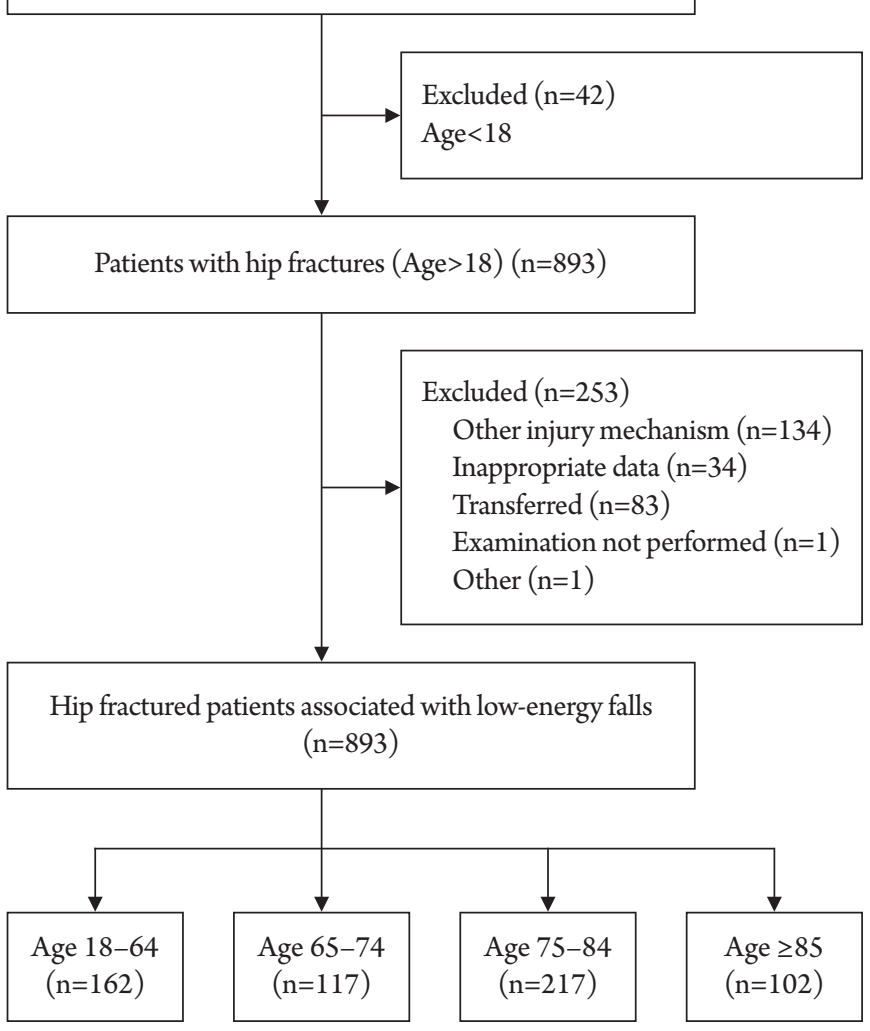

Fig. 1. Diagram of patients categories. proportion was significantly higher in older patients than in non-older patients ( $4.7 \%$ vs. $95.3 \%$, $\mathrm{p}<0.001)$. Additionally, the incidence of femur intertrochanteric fractures in the middle-old to oldest-old patients was significantly higher than in the non-older adults ( $92 \%$ vs. $8 \%$, p $<0.001 ; 88.3 \%$ vs. $11.7 \%$, p < 0.001 ), but no significant difference was observed between the young-old patients and the non-older adult patients ( $58.8 \%$ vs. $41.2 \%, \mathrm{p}=0.145)$. There was no significant difference in the frequency of femoral neck fracture and femoral subtrochanteric fracture (Table 1).

Of the 117 young-old patients, 48 (14\%) were men and 69 (59\%) were women; of the 217 middle-old patients, 57 (26.3\%) were men and 160 (73.7\%) were women; of the 102 oldest-old patients, 21 (20.6\%) were men and $81(79.4 \%)$ were women. The differences in sex ratios between the three patient groups were statistically significant $(p=0.002)$. The frequency of drinking alcohol was higher in the middle-old patients than in the young-old and oldest-old patients but it was not statistically significant $(\mathrm{p}=0.392)$. Among the underlying diseases surveyed, the frequencies of stroke ( $21.4 \%$ vs. $23.5 \%$ vs. $21.6 \%, p=0.877$ ) was higher in the middle-old patients, while those of dementia ( $0.9 \%$ vs. $5.1 \%$ vs. $14.4 \%, \mathrm{p}<0.001)$ and osteoporosis $(29.9 \%$ vs. $43.8 \%$ vs. $70.6 \%$ $\mathrm{p}<0.001)$ were higher in the oldest-old patients and the frequencies of Parkinson disease ( $6.8 \%$ vs. $4.6 \%$ vs. $4.9 \%, p=0.673)$ and cancer $(7.7 \%$ vs. $3.7 \%$ vs. $2.9 \%, p=0.164)$ were higher in the young-old than the middle-old to oldest-old patients but only the frequencies of dementia and osteoporosis were statistically significant. The time of accident was trended higher for each group between 12:00 and 17:59 but was not statistically significant $(p=0.114)$. The frequencies of intertrochanteric fractures were significantly higher in middle-old and oldest-old patients than that in young-old patients ( $8.5 \%$ vs. $36.9 \%$ vs. $52.0 \%$, p < 0.001$)$ and, while Tronzo type 3 was tend to be higher in middle and oldest-old patient groups, the difference was not statistically significant $(p=0.907)$. The frequency of unfavorable outcomes was trended higher in the middle and oldest-old patients but was also not statistically significant ( $0 \%$ vs. $1.4 \%$ vs. $2.9 \%, \mathrm{p}=0.238$ ) (Table 2 ).

Investigation of the relationship between femoral intertrochanteric fractures in older patients revealed that age $>75$ years, sex, and osteoporosis were statistically significant $(p<0.001, p=0.020$, $\mathrm{p}<0.001$ ), while other underlying conditions such as time of accident, drinking alcohol at the time of accident, stroke, dementia, Parkinson disease, and cancer were not. No significant associations were observed between femoral neck and femoral subtrochanteric fractures (Table 3).

A binary logistic regression of the factors that showed statistically significant differences in the single-variable analysis of the relationship between femoral intertrochanteric fractures in the older 
Table 1. Comparisons of incidence frequencies of femoral intertrochanteric fractures according to age group

\begin{tabular}{|c|c|c|c|c|c|c|}
\hline & Intertrochanteric fracture & & Non-intertroc & teric fracture & & \\
\hline & $(n=150)$ & Total $(n=448)$ & $\operatorname{FNF}(n=130)$ & $\operatorname{STF}(n=15)$ & Others ${ }^{*}(n=303)$ & $\mathrm{p}$-value \\
\hline Comparison 1 & & & & & & $<0.001$ \\
\hline Non-older adults (A) & $7(4.7)$ & $155(34.6)$ & $13(10.0)$ & $5(33.3)$ & $137(45.1)$ & \\
\hline Older adults (B) & $143(95.3)$ & $293(65.4)$ & $117(90.0)$ & $10(66.7)$ & $166(54.9)$ & \\
\hline Comparison 2 & & & & & & 0.145 \\
\hline Non-older adults (A) & $7(41.2)$ & $155(59.2)$ & $13(26.5)$ & $5(55.6)$ & $137(67.8)$ & \\
\hline Young-old (B1) & $10(58.8)$ & $107(40.8)$ & $36(73.5)$ & $4(44.4)$ & $65(32.2)$ & \\
\hline Comparison 3 & & & & & & $<0.001$ \\
\hline Non-older adults (A) & $7(8.0)$ & $155(53.1)$ & $13(19.4)$ & $5(45.5)$ & $137(63.1)$ & \\
\hline Middle-old (B2) & $80(92.0)$ & $137(46.9)$ & $54(80.6)$ & $6(54.5)$ & $80(36.9)$ & \\
\hline Comparison 4 & & & & & & $<0.001$ \\
\hline Non-older adults (A) & $7(11.7)$ & $155(76.0)$ & $13(32.5)$ & $5(100)$ & $137(86.2)$ & \\
\hline Oldest-old (B3) & $53(88.3)$ & $49(24.0)$ & $27(67.5)$ & $0(0.0)$ & $22(13.8)$ & \\
\hline Comparison 5 & & & & & & $<0.001$ \\
\hline Young-old (B1) & $10(11.1)$ & $107(43.9)$ & $36(40.0)$ & $4(40.0)$ & $65(44.8)$ & \\
\hline Middle-old (B2) & $80(88.9)$ & $137(56.1)$ & $54(60.0)$ & $6(60.0)$ & $80(55.2)$ & \\
\hline Comparison 6 & & & & & & $<0.001$ \\
\hline Young-old (B1) & $10(15.9)$ & $107(68.6)$ & $36(57.1)$ & $4(100)$ & $65(74.7)$ & \\
\hline Oldest-old (B3) & $53(84.1)$ & $49(31.4)$ & $27(42.9)$ & $0(0.0)$ & $22(25.3)$ & \\
\hline Comparison 7 & & & & & & 0.008 \\
\hline Middle-old (B2) & $80(60.2)$ & $137(73.7)$ & $54(66.7)$ & $6(100)$ & $80(78.4)$ & \\
\hline Oldest-old (B3) & $53(39.8)$ & $49(48.0)$ & $27(33.3)$ & $0(0.0)$ & $22(21.6)$ & \\
\hline
\end{tabular}

Values are presented as number (\%).

Patients were divided into two main group: 18-64 years (group A; non-older adults, n=7) and $\geq 65$ years (group B; older adults, $n=143$ ). Group B was again subdivided into three subgroups: 65-74 years (group B1; young-old, $n=10$ ), $75-84$ years (group B2; middle-old, $n=80$ ), and $\geq 85$ years (group B3; oldest-old, $\mathrm{n}=53$ ).

FNF, femoral neck fracture; STF, subtrochanteric fracture.

*Others included femoral greater trochanteric fractures, femoral shaft fractures, and distal femoral fractures.

${ }^{+}$By chi-square and Fisher exact tests, respectively.

patient group showed that age $>75$ years and osteoporosis were statistically significant $(\mathrm{p}<0.001 ; \mathrm{p}=0.004)$. The odds ratio of femur intertrochanteric fractures among older patients was 6.620 times (95\% confidence interval [CI], 3.309-13.245) higher for those aged $>75$ years and 1.906 times (95\% CI, 1.231-2.949) higher in those with osteoporosis (Table 4).

\section{DISCUSSION}

The prevalence and mortality rates of trauma are higher among older adults than those among younger adults ${ }^{26,27)}$ due to the decreased ability of older adults to cope with aging processes such as reduced visual acuity, hearing loss, physical disability, drug use, baseline disease, and cognitive impairment. ${ }^{28,29)}$ These characteristics differ in their clinical patterns from trauma between older and younger adults. Therefore, the actual severity of the trauma tends to be underestimated at an earlier stage. ${ }^{30)}$ Moreover, older patients more often require long-term and complicated in-patient treat- ment processes, which has led to increased interest and study of older adults in trauma fields. ${ }^{31}$

In the United States, about 340,000 femoral fractures are reported annually. ${ }^{32)}$ Femoral fractures, the most common major fracture among older adults, are also the most common causes of hospitalization in older trauma patients. ${ }^{4)}$ The mechanism of fracture is falling from a standing height. In particular, the reason for the high frequency in older adults is related to reduced femoral bone strength with increasing age. ${ }^{4)}$

With the increase in the average life expectancy, the older population has increased and their quality of life has improved due to social and economic development in this population. The older adult population consists of different age groups, from relatively healthy 65 -year-olds to older adults $>85$ years of age who have difficulty moving; therefore, it is difficult to classify them as a single group. ${ }^{33)}$ Therefore, viewing all older persons aged $>65$ years using the same standards may be inappropriate and establishing a finer-scale classification is necessary. Young-old persons are rela- 
Table 2. Comparisons of characteristics between the young-old, middle-old, and oldest-old age groups

\begin{tabular}{|c|c|c|c|c|}
\hline & Young-old (65-74y) & Middle-old (75-84 y) & Oldest-old $(\geq 85 y)$ & p-value ${ }^{*}$ \\
\hline Number of patients & 117 & 217 & 102 & \\
\hline Sex & & & & 0.002 \\
\hline Male & $48(41.0)$ & $57(26.3)$ & $21(20.6)$ & \\
\hline Female & $69(59.0)$ & $160(73.7)$ & $81(79.4)$ & \\
\hline Drunken state & $2(1.7)$ & $4(1.9)$ & $0(0.0)$ & 0.392 \\
\hline \multicolumn{5}{|l|}{ Underlying disease } \\
\hline Cerebrovascular accident & $25(21.4)$ & $51(23.5)$ & $22(21.6)$ & 0.877 \\
\hline Dementia & $1(0.9)$ & $11(5.1)$ & $15(14.4)$ & $<0.001$ \\
\hline Osteoporosis & $35(29.9)$ & $95(43.8)$ & $72(70.6)$ & $<0.001$ \\
\hline Parkinson's disease & $8(6.8)$ & $10(4.6)$ & $5(4.9)$ & 0.673 \\
\hline Malignancy & $9(7.7)$ & $8(3.7)$ & $3(2.9)$ & 0.164 \\
\hline Accident time & & & & 0.114 \\
\hline $0: 00-5: 59$ & $6(5.1)$ & $25(11.5)$ & $15(14.7)$ & \\
\hline $6: 00-11: 59$ & $29(24.8)$ & $69(31.8)$ & $31(30.4)$ & \\
\hline $12: 00-17: 59$ & $51(43.6)$ & $78(35.9)$ & $32(31.4)$ & \\
\hline $18: 00-23: 59$ & $31(26.5)$ & $45(20.7)$ & $24(23.5)$ & \\
\hline Intertrochanteric fracture & $10(8.5)$ & $80(36.9)$ & $53(52.0)$ & $<0.001$ \\
\hline Subtype (Tronzo classification) & & & & 0.907 \\
\hline Type 1 & $2(20.0)$ & $7(8.8)$ & $8(15.1)$ & \\
\hline Type 2 & $1(10.0)$ & $12(15.0)$ & $9(17.0)$ & \\
\hline Type 3 & $3(30.0)$ & $36(45.0)$ & $20(37.7)$ & \\
\hline Type 4 & $4(40.0)$ & $23(28.7)$ & $15(28.3)$ & \\
\hline Type 5 & $0(0)$ & $2(2.5)$ & $1(1.9)$ & \\
\hline Unfavorable outcome $\dagger$ & $0(0)$ & $3(1.4)$ & $3(2.9)$ & 0.238 \\
\hline
\end{tabular}

Values are presented as number (\%).

${ }^{*}$ By chi-square and Fisher exact tests, respectively.

${ }^{+}$Unfavorable outcome indicates cases of transfer or death due to complications.

tively healthy and active. They often enjoy continuous self-development and active leisure as they did when they were younger. In contrast, older adults $>75$ years of age are more likely to experience fatal diseases and often have a combination of geriatric diseases such as heart disease, hypertension, diabetes, cancer, and osteoporosis. These geriatric diseases are chronic degenerative diseases that require long-term treatment and increased medical resource utilization and medical costs. ${ }^{34,35)}$ The middle-old to oldest-old individuals experience fewer activities of daily living compared to those in young-old individuals. ${ }^{36)}$ Moreover, chronic disease morbidity significantly increases, which results in a variety of dysfunction, loss of function, and pathological changes. ${ }^{37)}$ Several studies have reported a significant increase in complications and mortality from various trauma in middle-old patients aged 75 years. ${ }^{38-40)}$ Additionally, the common risk factors for minor falls, such as weakness of balance or strength, ${ }^{41)}$ increase in the middle-old and oldest-old individuals. ${ }^{37)}$ Hence, these populations are more vulnerable to minor falls compared to the other age groups. Hip injuries due to minor falls in older adults are the most common injuries. ${ }^{42)}$
In particular, femur intertrochanteric fractures have the highest mortality rate among all femoral fractures ${ }^{43)}$ and have emerged as an important study in the area of trauma for in older adults. However, few studies have subdivided older adults with minor fall injury according to age. Specifically, no study has assessed the incidence of femoral intertrochanteric fractures due to minor falls among middle and oldest-old patients.

Compared to young-old individuals, middle and oldest-old individuals are expected to have more severe hip impact and damage from fall injuries. In our study, the incidence of femur intertrochanteric fractures did not vary significantly between young-old and non-old individuals; however, the incidence of femur intertrochanteric fractures was approximately 13 times higher in the middle-old and oldest-old individuals than that in young-old individuals. This result is significant because it differs from those of previous studies that showed an increased frequency of femoral intertrochanteric fractures in individuals aged 65 years. ${ }^{12,25,44)}$

Additionally, as age and underlying disease increase, bone mineral density decreases significantly, making patients more vulnera- 
Table 3. Clinical variables related to the development of femoral intertrochanteric fractures from minor falls in older patients

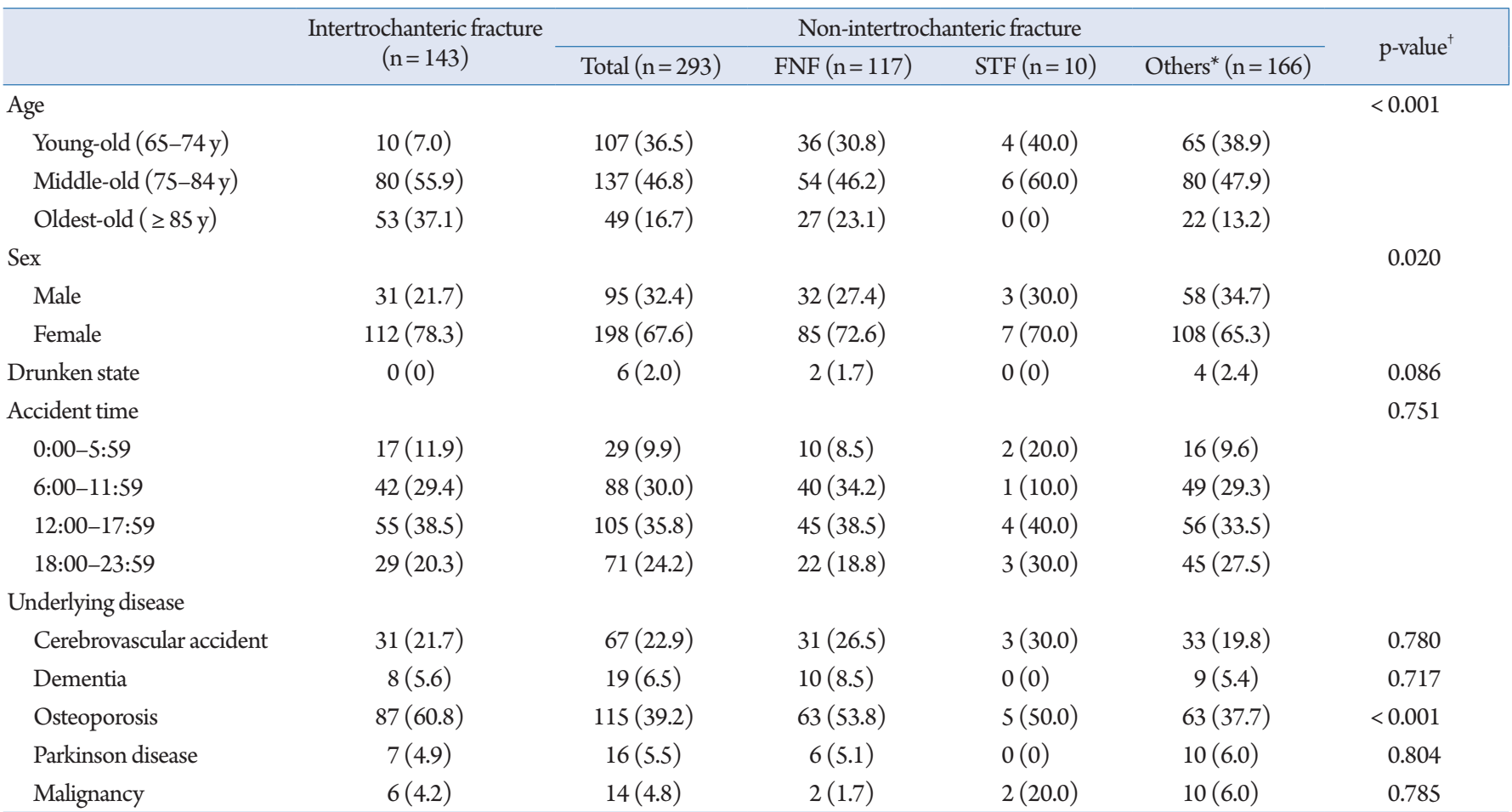

Values are presented as number (\%).

FNF, femoral neck fracture; STF, subtrochanteric fracture.

*Others included femoral greater trochanteric fractures, femoral shaft fractures, and distal femoral fractures.

${ }^{\dagger}$ By chi-square and Fisher exact tests, respectively.

Table 4. Risk factors related to the development of femoral intertrochanteric fractures from minor falls in older patients by multivariate logistic regression analysis

\begin{tabular}{|c|c|c|c|c|}
\hline & ספת & & & ( \\
\hline & K & Low & High & p-value \\
\hline Gender & 1.233 & 0.743 & 2.047 & 0.417 \\
\hline Middle and oldest-old & 6.620 & 3.309 & 13.245 & $<0.001$ \\
\hline Middle-old (75-84y) & 6.248 & 3.089 & 12.637 & $<0.001$ \\
\hline Oldest-old ( $\geq 85 \mathrm{y})$ & 11.573 & 5.436 & 24.639 & $<0.001$ \\
\hline Osteoporosis & 1.906 & 1.231 & 2.949 & 0.004 \\
\hline
\end{tabular}

OR, odds ratio; CI, confidence interval.

${ }^{*} \mathrm{p}<0.05$ in multivariate analysis were entered into the binary logistic regression analysis.

ble to fractures. ${ }^{45)}$ In particular, studies have shown that a decrease in bone density exponentially increases the incidence of intertrochanteric fractures. ${ }^{46)}$ Our study also showed that osteoporosis increases the incidence of femoral intertrochanteric fractures by approximately 1.9-fold, a finding consistent with those of previous studies.

According to the World Health Organization, the number of patients with hip fractures is expected to significantly increase from 1.7 million in 1990 to 6.3 million in 2050 ; $^{47)}$ furthermore, the frequency of femoral intertrochanteric fractures in Korea is also in- creasing. ${ }^{48)}$ Although the number of patients visiting the emergency center due to hip injuries is increasing, it is difficult to diagnose all intertrochanteric fractures using a plain radiograph alone because emergency centers are pressed for time in the field. Additionally, the accident mechanism is an important factor in predicting the severity of trauma in patients; hip injuries caused by minor falls are more frequent and may seem relatively more minor than other severe traumas. Therefore, intertrochanteric fractures are often ruled out if a fracture line is not visible on simple radiographs. Additionally, while hip CT is often considered in cases in which 
diagnosis is difficult using radiography, patients may not want to be examined because of the relatively high cost of CT scans.

In our study, the incidence of femoral intertrochanteric fractures caused by minor fall injuries in the middle-old and oldest-old patients was higher than that in young-old patients. Therefore, the imaging results of middle-old and oldest-old patients should be carefully read even if the patients do not complain of pain. If necessary, hip CT should also be performed. Moreover, increased attention should be paid to middle-old and oldest-old patients with stroke or dementia than to young-old patients.

The limitation of this study was that it was conducted in a single emergency center located in a metropolitan urban area where people with relatively good nutrition or high socioeconomic status were more likely to reside; thus, there may be bias in the patient distribution or propensity. Additional multicenter studies including local emergency centers will provide more accurate results on the incidence of femoral intertrochanteric fractures according to age groups of older patients.

\section{CONFLICT OF INTEREST DISCLOSURES}

The researchers claim no conflicts of interest.

\section{REFERENCES}

1. Korean Statistical Information Service [Internet]. Daejeon: Statistics Korea; c2019 [cited 2019 Sep 10]. Available from: http:// kosis.kr/eng/.

2. Choi SJ. Ageing society issues in Korea. Hong Kong: Asia-Pacific Institute of Aging Studies; 2007.

3. Cevik Y, Dogan NO, Das M, Karakayali O, Delice O, Kavalci C. Evaluation of geriatric patients with trauma scores after motor vehicle trauma. Am J Emerg Med 2013;31:1453-6.

4. Wang SJ. Introduction of geriatric emergency medicine. J Korean Geriatr Soc 2003; 7:1-13.

5. Harvey LA, Close JC. Traumatic brain injury in older adults: characteristics, causes and consequences. Injury 2012;43:18216.

6. Lee JH, Ahn EM, Kim GE, Jeong YK, Kim JH, Kim JH, et al. The effects of falling and fear of falling on daily activity levels in the elderly residing in Korean rural community. J Korean Geriatr Soc 2009; 13:79-88.

7. Reyes-Ortiz CA, Al Snih S, Markides KS. Falls among elderly persons in Latin America and the Caribbean and among elderly Mexican-Americans. Rev Panam Salud Publica 2005; 17:362-9.

8. Bradley C. Trends in hospitalisations due to falls by older people, Australia: 1999-00 to 2010-11. Canberra: Australia Institute of
Health and Welfare; 2013.

9. Lee H, Bein KJ, Ivers R, Dinh MM. Changing patterns of injury associated with low-energy falls in the elderly: a 10-year analysis at an Australian Major Trauma Centre. ANZ J Surg 2015;85:230-4.

10. Sterling DA, O’Connor JA, Bonadies J. Geriatric falls: injury severity is high and disproportionate to mechanism. J Trauma 2001;50:116-9.

11. Parker S, Afsharpad A. Ground-level geriatric falls: a not-so-minor mechanism of injury. Case Rep Orthop 2014;2014:164632.

12. Lauritzen JB. Hip fractures: incidence, risk factors, energy absorption, and prevention. Bone 1996;18(1 Suppl):65S-75S.

13. Forte ML, Virnig BA, Kane RL, Durham S, Bhandari M, Feldman R, et al. Geographic variation in device use for intertrochanteric hip fractures. J Bone Joint Surg Am 2008;90:691-9.

14. Jiang HX, Majumdar SR, Dick DA, Moreau M, Raso J, Otto DD, et al. Development and initial validation of a risk score for predicting in-hospital and 1-year mortality in patients with hip fractures. J Bone Miner Res 2005;20:494-500.

15. Chana R, Noorani A, Ashwood N, Chatterji U, Healy J, Baird P. The role of MRI in the diagnosis of proximal femoral fractures in the elderly. Injury 2006;37:185-9.

16. National Center for Health Statistics. National trends in injury hospitalizations, 1979-2001. Hyattsville, MD: National Center for Health Statistics; 2005.

17. Goodmanson NW, Rosengart MR, Barnato AE, Sperry JL, Peitzman AB, Marshall GT. Defining geriatric trauma: when does age make a difference? Surgery 2012;152:668-75.

18. Do HK, Lim JY. Rehabilitation strategy to improve physical function of oldest-old adults. J Korean Geriatr Soc 2015;19:6170.

19. Crews DE, Zavotka S. Aging, disability, and frailty: implications for universal design. J Physiol Anthropol 2006;25:113-8.

20. Suzman R, Riley MW. Introducing the "oldest old”. Milbank Mem Fund QHealth Soc 1985;63:177-86.

21. Yasumura S. Frequency of falls and bone fractures in the elderly. Japan Med Assoc J 2001;44:192-7.

22. Kim KI, Jung HK, Kim CO, Kim SK, Cho HH, Kim DY, et al. Evidence-based guideline for fall prevention in Korea. J Korean Geriatr Soc 2016;20:1-28.

23. Masud T, Morris RO. Epidemiology of falls. Age Ageing 2001;30:3-7.

24. Tronzo RG. Symposium on fractures of the hip. Special considerations in management. Orthop Clin North Am 1974;5:571-83.

25. Lauritzen JB, Schwarz P, Lund B, McNair P, Transbol I. Changing incidence and residual lifetime risk of common osteoporosis-related fractures. Osteoporos Int 1993;3:127-32. 
26. Ahn BM, Choi SP, Park JH, Wee JH, Hong SY, Jeong SK. Clinical characteristics and risk factors in severely injured elderly trauma presenting to emergency department. J Korean Geriatr Soc 2015;19:138-46.

27. Lee Y. Evidence-based prevention of frailty in older adults. J Korean Geriatr Soc 2015;19:121-9.

28. Roy CW, Pentland B, Miller JD. The causes and consequences of minor head injury in the elderly. Injury 1986;17:220-3.

29. Morfitt JM. Falls in old people at home: intrinsic versus environmental factors in causation. Public Health 1983;97:115-20.

30. Peschman J, Neideen T, Brasel K. The impact of discharging minimally injured trauma patient: does age play a role in trauma admission? J Trauma 2011;70:1331-6.

31. Choi GJ, Lee BC, Sun ML. Characteristics and illness behaviors of the elderly patients who visited emergency department by emergency medical services. Korean J Fam Pract 2012;2:241-9.

32. Lichtblau S. Hip fracture. Surgical decisions that affect medical management. Geriatric 2000;55:50-2. 55-6.

33. Yeo HN, Kim YK. A phenomenological study on the re-employment experiences of the young-old. J Korea Acad-Ind Coop Society 2018;19:168-78.

34. Bullain SS, Corrada MM. Dementia in the oldest old. Continuum (Minneap Minn) 2013;19(2 Dementia):457-69.

35. Bullain SS, Corrada MM, Shah BA, Mozaffar FH, Panzenboeck $\mathrm{M}$, Kawas $\mathrm{CH}$. Poor physical performance and dementia in the oldest old: the 90+ study. JAMA Neurol 2013;70:107-13.

36. Quinn TJ, McArthur K, Ellis G, Stott DJ. Functional assessment in older people. BMJ 2011;343:d4681.

37. Joe S, Lee I, Park B. Factors influencing health-related quality of life of young adults and elderly with multimorbiditiy: a secondary analysis of the 2013 Korea Health Panel data. J Korean Acad Community Health Nurs 2016;27:358-69.
38. Lee DS, Park JT. Surgical outcome of traumatic brain injury in the elderly. J Korean Neurotraumatol Soc 2006;2:37-42.

39. Kim SK, Jeong KY, Lee JS, Choi HS, Hong HP, Ko YG. Risk of traumatic intracranial hemorrhage from low-energy falls in the oldest-old patients. Ann Geriatr Med Res 2016;20:221-8.

40. Yang YM, Kim ES. The status of incidence and the prognostic factors in geriatric trauma patients. J Korean Soc Traumatol 2004;17:37-48.

41. Evans D, Hodgkinson B, Lambert L, Wood J. Falls risk factors in the hospital setting: a systematic review. Int J Nurs Pract 2001;7:38-45.

42. Hefny AF, Abbas AK, Abu-Zidan FM. Geriatric fall-related injuries. Afr Health Sci 2016;16:554-9.

43. Kesmezacar H, Ayhan E, Unlu MC, Seker A, Karaca S. Predictors of mortality in elderly patients with an intertrochanteric or a femoral neck fracture. J Trauma 2010;68:153-8.

44. Karagas MR, Lu-Yao GL, Barrett JA, Beach ML, Baron JA. Heterogeneity of hip fracture: age, race, sex, and geographic patterns of femoral neck and trochanteric fractures among the US elderly. Am J Epidemiol 1996;143:677-82.

45. Glynn NW, Meilahn EN, Charron M, Anderson SJ, Kuller LH, CauleyJA. Determinants of bone mineral density in older men.J Bone Miner Res 1995; 10:1769-77.

46. Melton LJ 3rd, Wahner HW, Richelson LS, O’Fallon WM, Riggs BL. Osteoporosis and the risk of hip fracture. Am J Epidemiol 1986;124:254-61.

47. World Health Organization. Osteoporosis: both health organizations and individuals must act now to avoid an impending epidemic. Geneva: World Health Organization; 1999.

48. Yoon BH, Lee YK, Kim SC, Kim SH, Ha YC, Koo KH. Epidemiology of proximal femoral fractures in South Korea. Arch Osteoporos $2013 ; 8: 157$. 